\title{
The Innovative Marketing Strategies of MTN Cameroon
}

\section{Francis Mbah Takwi, Atingwa Corlence, Vivian Neba Akosso, Bejanga Sharon, Kiven Cynthia}

Faculty of Business Management and Sustainability, Information and Communication Technology University USA, Yaounde, Cameroon

\section{Email address:}

francis.takwi@ictuniversity.org (F. M. Takwi),Atingwa.Corlence@ictuniversity.org (A. Corlence), v.akosso@ictuniversity.org (V. N. Akosso), bejanga_sharon@yahoo.com (B. Sharon), kiven.cynthia@ictuniversity.org (K. Cynthia)

\section{To cite this article:}

Francis Mbah Takwi, Atingwa Corlence, Vivian Neba Akosso, Bejanga Sharon, Kiven Cynthia. The Innovative Marketing Strategies of MTN Cameroon. American Journal of Operations Management and Information Systems. Vol. 6, No. 2, 2021, pp. 16-20.

doi: 10.11648/j.ajomis.20210602.11

Received: September 29, 2020; Accepted: October 19, 2020; Published: June 3, 2021

\begin{abstract}
A successful marketing strategy must tell an organization where there will want to be on a long term basis that is why is is often said that marketing strategy is a continuous process. Marketing strategy is seen as the business logic in which a firm can achieve its performance in the business organization there is no activity where the marketer must not therefore make a right decision about the four marketing mis strategies which is the price the product place or distribution and the promotion. This strategies must be done to ensure that a product performs it objectives in the market. Mobile cellular networks have revolutionized the communication sector to the extent that mobile phones have become the most preferred method of communication across the globe. MTN Cameroon was the second mobile telephone company established in year 2000. It is a private institution and it enjoyed its existence without a major competitor till the Emergence of it competitors Orange and Nextel. However MTN have been involved is very serious market strategies outsmarting one another in the process. The difference in their market strategies could better explain such margins. This assertion would better be justified through an indepth research on the marketing strategies of MTN Cameroon and the impact they have had on their company. MTN great market share and potential and equally its productivity in business all through this long period of time and comparative advantage over time and maintenance of this position as telecommunications leader can logically be attributed to the mind blowing marketing strategies that this company uses, its marketing strategy and equally the advertisement secures the market shares and hence one can logically conclude say from the analysis of our case study- MTN Cameroon that good marketing strategies and equally positive good practices ensures the performance of the company and hence success both in the short and long run alongside a greater market share and comparative advantage over all other.
\end{abstract}

Keywords: Marketing Mix, Strategic Marketing, Business Innovation, MTN

\section{Introduction}

This article elaborates the product, pricing, advertising \& distribution strategies and other strategies like grow of new services, improve customer service, performance through marketing intelligence, aggressive brand visibility, free bundles and MTN services. All this strategies are used by MTN and hence their organizational performance. [2]

Research in telecommunication sector in Cameroon is probably long overdue as telecommunication is now the hub for the economic development of the country. It is one of the most important factors that drive trade and economy in general. The Invention of mobile phones has been a milestone in the telecommunication industry. Since the introduction of CAMTEL, MTN, ORANGE AND NEXTEL networks in Cameroon, mobile phones have become the most preferred method of communication by the majority of Cameroonians. This is because of easy accessibility and convenience making the transfer of information very quick. MTN was the second mobile company to come to Cameroon and started its operations in the year 2000. The coming of Orange and Nextel networks has cause the telecommunications to involve in a tense competition to the extent that MTN has overtaken in terms of market share. [3]

It should also be pointed out that the market war between the telecommunication companies has been fought mainly along their marketing strategies. As such their growth, success or failure can best be explained in terms of their marketing strategies. Johnson observes that marketing is accountable for the present and responsible for the future 
growth and success of an organization [6]. This is why this study concentrates much on the marketing strategies of MTN CAMEROON mobile company to ascertain how they have contributed to their performance over the years [12].

Strategic marketing management: is a method through which an organisation differentiates itself from its competition by focusing on its strengths to provide better service and value to its customers. In a nutshell, the goal of strategic marketing is to make the most of an organization's positive differentiation over its competition through the consumers'. Organizational performance comprises the actual output or results of an organization as measured against its intended outputs (or goals and objectives). [8]

\subsection{Problem Statement}

Mobile cellular networks have revolutionized the communication sector to the extent that mobile phones have become the most preferred method of communication across the globe. MTN Cameroon was the second mobile telephone company established in year 2000. [4] It is a private institution and it enjoyed its existence without a major competitor till the Emergence of it competitors Orange and Nextel. However MTN have been involved is very serious market strategies outsmarting one another in the process. The difference in their market strategies could better explain such margins. This assertion would better be justified through an in-depth research on the marketing strategies of MTN Cameroon and the impact they have had on their company.

\subsection{Objectives of the Study}

The aim of this research is to assess the role of marketing strategies on the performance of MTN Cameroon through a comparative study of the business strategies of the company. It is believed that the growth and success of every company depends on their marketing strategies.

The specific objectives of the research were:

To understand the marketing strategies of MTN Cameroon

To assess customers ${ }^{\text {ee }}$ response to the implementation of marketing strategies.

To assess the impact of marketing strategies on the performance of MTN Cameroon

\subsection{Research Questions}

The following were the research questions for the study:

1. What are main strategies used by MTN

2. How have the subscribers responded to different marketing strategies employed by MTN

3. What has been the impact of the marketing strategies on the overall performance of MTM

4. What is their marketing intelligence strategies

\subsection{Strategic Evolution of MTN}

MTN Cameroon (MTN) is a subsidiary of the MTN Group created on 15 February 2000, following the acquisition by MTN International of the first mobile operator in Cameroon, CAMTEL Mobile. In 20 years of activity, MTN Cameroon has imposed itself as the leader of the electronic communications market in Cameroon because of it products and services and also recorded an exponential increase of $26.25 \%$ in its customer base, with nearly 2 million new subscribers gained in fiscal year 2019. With 10.1 million subscribers and 49.5\% market share as of 31 December 2019, MTN is the undisputed leader in the Electronic Communications sector in Cameroon. This solid performance is the result of the customer-oriented strategy implemented by the company with major investments in network expansion and quality improvement. The company has also placed special emphasis on the development of its mobile money business which is today not only the most available and secure mobile wallet in Cameroon. Commenting on the publication of the annual results, Hendrik Kasteel, Chief Executive Officer of MTN Cameroon said: "Thanks to the confidence of our clients and extraordinary commitment of all our teams, we have been able to achieve a very good performance in a difficult environment. With 10 million subscribers and improved positive performance quarter after quarter since the end of 2018, MTN Cameroon is now well positioned to enter a new phase of growth. In 2020, as we celebrate 20 years of presence in Cameroon, the company is committed to bring more value to its customers so that they are more satisfied and prouder to be part of the largest community in Cameroon. Equally, we plan on continuing to invest in order to drive Cameroon's digital agenda. [13]

\section{Methodology}

Research methodology is a systematic means to solve a problem or give an answer to a question. It is essential for the researcher to design a methodology for the problem chosen. It is science of studying how research is to be carried out. Mainly research methodology describes how data are collected, what tools are used for this purpose and from whom the data are collected. Thus, this section contains research design, data collection, sample selection and procedure for data analysis. [1]

The designed used for this research is an approach of quantitative method. The design is based on following the techniques of quantitative method. A structured question survey method is applied in this study. Quantitative research refers to the systematic empirical investigation of social phenomena via statistical, mathematical or numerical data or computational techniques. In layman's terms, this means that the quantitative researcher asks a specific, narrow question and collects a sample of numerical data from participants to answer the question. The researcher analyzes the data with the help of statistics. [7]

Quantitative research is often contrasted with qualitative research, which is the examination, analysis and interpretation of observations for the purpose of discovering underlying meanings and patterns of relationships, including classifications of types of phenomena and entities, in a manner that does not involve mathematical models.

Among different alternative categories of research, survey method with unstructured interviews was applied in this 
study which was quite difficult in getting due to the COVID19 pandemic which is spreading daily. This is the interview guide was use to probe into the marketing strategies of MTN Cameroon. [9]

This research is conducted based on Yaoundé Capital City of Cameroon. Information of the study was collected from random mobile users of Yaoundé municipality. The population of the research is the entire people of Yaoundé (Center Region) of Cameroon, to be more narrowly the people of Yaoundé 1 who are the user of MTN service. The researcher has chosen random MTN clients for the research. People from diverse age groups, occupation, gender, religion etc. that implies having diverse demographics and psychographic characteristics uses mobile communication for various communicative purpose. To conduct the survey among population consists of mobile phone users, a sample of 110 users had been taken out.

The research conducted on the sample of 110 respondents from the cities of Yaoundé. As this study chose to apply factor analysis, and 44 questions (14 for obtaining basic information about the mobile users and 30 questions for surveying their opinions) of the questionnaire had been subjected to this analysis Taking acknowledge of the possibility of facing strict corporate secrecy the questionnaire will not apply to the mobile operator company but to mobile phone users only.

Measurement is often regarded as being only a means by which observations are expressed numerically in order to investigate causal relations or associations. In order to make an effective quantitative research, the sample of 110 respondents is being chosen. The sample was made on the basis of using various telecommunication operators' connection. The sample mainly collected from Yaoundé. The respondent chose as random where discrimination in term of age, gender, race or ethnicity is completely avoided. Asking questions and getting answer is a much harder task than it may seem at first The interview etiquette consists of questions regarding the conditions of marketing myopia and how it is connected with Cameroon's telecom industry especially with MTN.

\section{Key Findings}

\subsection{Marketing Strategies of MTN Cameroon}

Marketing strategies as already observed, play a crucial role in the overall performance of MTN Cameroon. A remarkable impact is on the growth of the networks. Sound marketing strategies have led MTN Cameroon to become the market leader in terms of market share despite being second mobile company to start its operations in Cameroon after CAMTEL [12]

MTN'S success is attributed to its product strategies, promotional strategies and distribution strategies. MTN has demonstrated that it is an innovative company by being the first to introduce MTN mobile money and services and the company benefited a lot from first mover advantage. MTN is also known for carrying out aggressive promotions advertising and even hosting events usually with huge grand prizes that attracted new subscribers. MTN is also very good with distribution strategies. It was able to cover a wide population than it rivals Nextel orange and even CAMTEL [12]

Significantly, marketing strategies are very essential for the growth and success of any company. This is more applicable to telecommunication industry which is usually marked by tense competition as network providers fight for subscribers. The aim of this study was to determine the role of marketing strategies in the performance of an organization using a comparative study of MTN strategic marketing is a method through which an organisation differentiates itself from its competition by focusing on its strengths to provide better service and value to its customers [11]. By and large, the goal of strategic marketing is to make the most of an organization's positive differentiation over its competition through the consumers' perspective. to achieve a great performance MTN used the following marketing strategies. [2]

Competitive tariffs and affordable prepaid bundles ( $\mathrm{mtn}$ go pan, MTN internet bundles, WhatsApp bundle, bundle sms, blackberry offers, voice bundles)

A connection -focused distribution methodology

Continued development of electronic vouchers distribution system

Aggressive brand visibility

Improvement of customer services

Innovative technology and product development

Stimulate of usage through consumer and trade promotions Quality and product innovation to gain first mover advantage

Introduction of new pricing solutions such as bundles

Performance Through Marketing Intelligence

The goal of marketing intelligence is to understand what happens outside the organization in order to increase competitiveness. Collecting all this intelligence can help in decision making it also involves the business environment in which the company fits and anything that can improve its performance that includes products and services, competitors customers and market segments. MTN Cameroon do marketing intelligence by sending agents to study the market this help them to know the products and services the customers needs and also how customers react to their services it also help them have a good knowledge about their current and potential customers. With marketing intelligence MTN also study his competitors and there are able to identify product differentiation and also acting fast in case of market changes and also learning from the mistakes of their competitors. there also identify what is missing in the market and that the customer needs it that is why MTN come up with new bundles to be able to satisfy their customers the knowledge of marketing intelligence has help the organization to identify points that can better explore the performance of the company [4].

Marketing intelligence also enables sales by providing the business team with information content and tools to well more efficiently which improves performance.

\subsubsection{Grow Sales of New Service}


MTN is known for its advertising strategies so when there introduce a new product there do a good advertising by sending messages to customers about the product and its benefit. There also offer the service free to customers so that it will help them have a good knowledge about the product this helps to attract customers and potential customers to consume the product or service and as a result increase productivity [8].

\subsubsection{Improve Customers Service}

MTN has improve on it customers service by giving them ways to provide feedback by making phone calls and sending messages to customers giving them contacts to call in case there have difficulty. By creating means of feedback makes it easier for them to improve on customers needs. There also ensure clear communications to customers by communicating to customers in both English and French and see to it that there solve customers problems. there also send birthday messages to their customers comedy, bible verses free airtime, free sms, free data. this improve in their customers service leads to productivity. [3]

\subsection{Marketing Mix Strategies}

The marketing strategies of MTN have been critical in the success of these company. MTN has a viable product strategies, aggressive promotions distribution strategies and pricing strategy. The marketing strategies of MTN IS concentrated on stimulating usage through sales promotion and product innovation to gain first mover advantage, MTN devised a multifaceted approach to marketing. Among others, MTN concentrated on providing competitive tariffs, connection based distribution, improved quality, customer retention and customer services, and aggressive brand visibility among others. Some of the remarkable differences in marketing strategies and customer perception about the MTN are highlighted below.

\subsubsection{Product Strategies}

MTN has demonstrated to be more innovative than other telecommunication companies in Cameroon since it is always the first to bring new products on the market. MTN has done very well in product development strategy such as the innovation of products like...

1. MTN gift

2. Entertainment

3. Me2U transfer

4. Mobile money

5. Biome

6. MTN YAMO

7. MTN prolongations

8. MTN mobile

9. MTN wanda

10. MTN wanda net

MTN have also introduced products like MTN Roam Like Home, which allows the customer to use the services without any kind of extra roaming cost. The business services also has a lot of aspects like MTN Cloud, Infrastructure, Network,
Software and Enterprise Mobility. MTN also have made the customers use the Mobile Money, so that they can make allow the customers to shop online using this method. The company has tied up with various key players to get this services to the customers. MTN also have a lot of other services like the games, music, lifestyle services, etc. which is available in the MTN Play.

\subsubsection{Distribution Strategies}

MTN has made its product available all through the countries of Africa and Middle East. We find that MTN makes sure that the products are available to the customers readily irrespectively of the places where they are. They form a reliable source and sufficient channels of distribution. They have an unaffected source of services, so that they make their customers happy. This is a way of keeping the customers happy. MTN have the recharge cards easily available to the people and also the same case with the other products of the company. The company believes that the happy customers are the secret to the success of the company. MTN makes sure, that they provide a supply of continuous network to each and every customers it has. MTN also has an indirect chain of distribution since it products passed through many channels before reaching the final consumer and there also send their products directly to the final consumer so he uses both directions and indirect distribution channel MTN uses uses an intensive distribution by ensuring that he covers much of the market as it can. MTN has a upper hand in distribution especially since it had better financial position than Other telecommunications in Cameroon. the selling of low cost phones, free internet bundles, free airtime and free sms which are crucial in market penetration. Customers are satisfied with MTN distribution which gives them a lot of benefits. MTN shares a great deal in distribution channels since most distributors stock mostly MTN products and therefore increases productivity.

\subsubsection{Promotion Strategies and Advertising}

The promotional and advertising strategy in the MTN marketing strategy is as follows:

MTN has been promoting itself in a heavy way. They mainly use the posters. The areas of Africa are covered with the hoardings. MTN have extensively marketed their brand. The company makes sure that the people are aware of their services. They are also promoting themselves through the word of mouth. They make the customers satisfied, that in turn makes the promotion indirectly. They also sponsor the most popular game in the country, i.e. football. MTN make sure the talents are nurtured properly. They sponsor the MTN Joyous Celebration. This is a great way to promote them among the people. They are getting to know about the brand. In the cycling event they also have a good no of sponsorship encouraging the people to take up cycling as a part of fitness. These various activities are good enough for the promotion of the company among the people. MTN Also has a very competitive advertising programs mainly on radios and television. There also print $t$ shirt caps books pen and give to their customers on promotion. MTN also uses the social media platform to do his promotions by posting videos on 
YouTube Facebook which makes its usage more fun. In addition to this MTN sponsors events like host artists and football for customers experience which is both inbound to provide attendees with quality informations and valuable content and also outbound in order to make the attendees buy their products. [4]

Sale promotions are still very important in telecommunication business. many subscribers enter promotional competitions. MTN also participate in sales promotions which encourages customers to buy more during this promotions and hence more profit. MTN customers are satisfied with sales promotion which increases consumption of MTN products and lead to their productivity.

\subsubsection{Mtn Pricing Strategies}

MTN has adopted a varying pricing structure in diverse packages to satisfy the customers. The company not only looks into the fact that they need to satisfy the customer, which is needed to a certain extent, but also looks to the profitability of itself. Affordable prices are offered to make the people take a heed of the products offered by MTN. They also have offers like MTN magic numbers which allows the customer to make free calls all through the day. There is like a CUG scheme which allows the customers to make calls at a cheaper rate to the five family of friends. There are other schemes which allows the customer to make phone calls at a cheap rate but not as cheap as the CUG type scheme. The data plans are also made easily available to customers so that they can pick and choose the type of plan which suits them. They are priced in such a way that they are attractive. This gives an overview of the MTN marketing mix pricing strategy. MTN also uses psychological pricing strategy my gathering the customers emotional response for example if a phone is 30000 there sell it for 29900 this makes the customer feel that the product is less expensive. In addition to this, MTN does price promotions like $u$ buy a certain amount of airtime and there give $u$ some for free, free bundles like voice bundle WhatsApp bundles bundle sms blackberry offers mobile internet bundles and international bundle. There also offer discounts so customers prefer buying the products to have the offer.

\subsubsection{Processes}

The processes of MTN is a standardized one. The process is well documented as it is followed all over the world. MTN even though has the standardized documentation, we find that they are customizing their products according to the need of the customers. Each and every customer have a kind of preference. This is how they make their customers satisfied and their loyalty is maintained. For simplicity, the functions of the company are carefully segregated based on the inter-connection.

\subsubsection{Physical Evidence}

MTN provides physical evidence through the website. The company has physical evidence through the sim cards. They also have handsets which are a source of physical evidence. The company gives gifts to the customers and the employees also. This is a way of providing the evidence to the people. Hence, this concludes the marketing mix of MTN.

\section{Conclusion}

From the a-for mentioned analyses and operations, bearing in mind MTN great market share and potential and equally its productivity in business all through this long period of time and comparative advantage over time and maintenance of this position as telecommunications leader can logically be attributed to the mind blowing marketing strategies that this company uses, its marketing strategy and equally the advertisement secures the market shares and hence one can logically conclude say from the analysis of our case study- MTN Cameroon that good marketing strategies and equally positive good practices ensures the performance of the company and hence success both in the short and long run along side a greater market share and comparative advantage over all other.

\section{References}

[1] Churchill, G. (1996) Basic marketing Research, The Dryden Press, New york.

[2] Davidson, J. (2017) offensive marketing strategies or how to make ur competitors followers, penguin, Harmondsworth.

[3] Groonroos, C. (2011), service management and marketing. Lexington Books, London.

[4] Kamdem E. 2004 le management et l'interculturalitr en afrique: experience camerounaise. Les presses de 1; universite laval IGNOU, (2012), MS 65: Marketing of Serices, Indira Gandhi National Open University, New Delhi.

[5] International Telecommunication Union, (1998), General Trends in Telecommunication Reform: Africa, International Telecommunication Union, Geneva, Switzerland.

[6] Johnson, G. \& Scholes, K. (1999), Exploring Corporate Strategy, Prentice Hall Europe, London.

[7] Kolb, B. (2008), Marketing Research: A Practical Approach, sage Publication India Pvt Ltd, New Delhi.

[8] Kotler, P. (1980), Marketing Management: Analysis, Planning and Control, Printice Hall, Inc, New Jersey.

[9] Kotler, P. (2003), Marketing Research, 11th edition, Prentice Hall, New Jersey.

[10] Lamb, C. W., Hair, J. F., \& McDaniel, C., (2008), Marketing, Thomson South-Western, Mason.

[11] Lovelock, C. H., (1996), Services Marketing, Printice Hall, Inc., New Jersey. Malawi's Telecom.

[12] Ngok evina J F 2014 la competivite des entreprises africaine: 1 cas du cameroun, la revue des sciences de gestion.

[13] McDonald, M. (1989), Ten Barriers to Marketing Planning, Journal of Marketing Management, Vol. 5, No 1, pp 1-18.

[14] MTN Cameroun Wikipedia 2020.

[15] NOU, (2011), MS 95: Research Methodology for Managerial Decision, Indira Gandhi National Open University, New Delhi. 